\title{
Development of a geographic information system-based decision support toolset to assess the feasibility of on-site wastewater treatment and disposal options in low permeability subsoils
}

\author{
Donata Dubber, Francesco Pilla, David Smyth, Nadeem Qazi,
}

Tim McCarthy and Laurence W. Gill

\begin{abstract}
Traditional on-site wastewater treatment systems have proven to be unsuitable in areas of low permeability subsoils, representing a risk to human health and the environment. With large areas being covered by low permeability tills, Ireland needs to consider alternative treatment and disposal options to be able to allow further development in these areas and to deal with polluting legacy sites. The paper describes the development and structure of a geographic information system (GIS)-based decision support toolset to evaluate possible alternative strategies for these sites. The programme takes as its initial input the location of an existing house located in an area of low permeability subsoils. Through a series of interconnected GIS geoprocesses the model outputs appropriate solutions for a site, ranking them in terms of environmental sustainability and cost. However, the final decisions are still dependent on on-site constraints so that each solution is accompanied by an alert message that provides additional information for the user to refine the output list according to the available local site-specific information.
\end{abstract}

Key words | decision support, domestic wastewater treatment, effluent disposal, geospatial modelling, septic tank, subsoil permeability

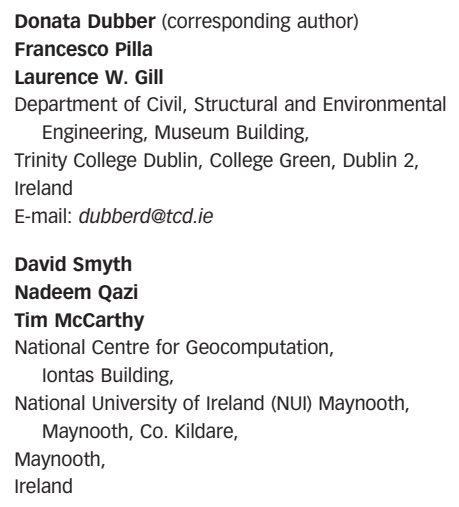

\section{INTRODUCTION}

The domestic wastewater of over one-third of the population in Ireland is treated by on-site wastewater treatment systems (OSWWTSs) (CSO 20II). For single houses in areas with no main drainage, on-site systems typically consist of septic tanks followed by a percolation area (soil attenuation system) (Gill et al. 2007). However, where the subsoil permeability is not sufficient to take the effluent load, surface ponding and runoff of pollutants to surface waters may occur. This represents a serious health risk and can also contribute to eutrophication in nutrient-sensitive water bodies. Hence, a lower limit on subsoil permeability was defined by the Irish Environmental Protection Agency (EPA) below which, at typical on-site wastewater hydraulic loads, percolation into the ground will not be fast enough and therefore discharge to ground is not permitted (EPA 2009). The proportion of the country with inadequate percolation is estimated to be 39\% (EPA 20I3) and according to the current legislation further house development in such areas would probably be very limited. Furthermore, existing houses in such areas may represent a risk to both human health and nearby surface waters.

Therefore the aim of this research is to investigate the potential for the application of alternative wastewater treatment and disposal options for rural housing in these areas and to develop a web-based geographic information systems (GIS) decision support toolset for local authority planners and managers to evaluate these strategies on the basis of both cost-benefit and environmental sustainability principles. 


\section{MATERIAL AND METHODS}

Geospatial modelling was conducted through the use of ESRI's ArcGIS 10 to evaluate the alternative strategies. Houses located outside of mapped sewered urban and rural areas were assumed to use a septic tank system for the treatment of their wastewater. To identify legacy septic tanks that are situated in areas of low subsoil permeability and therefore potentially present the highest risk of surface water pollution, a map specifying the likelihood of inadequate percolation for OSWWTSs in Ireland was used which combines the relationship between groundwater vulnerability, recharge, soil/subsoil permeability and surface runoff (EPA 20I3). This map was used to clip the GIS layer of assumed septic tanks and to extract the site locations of interest. The alternative on-site disposal systems which were considered as possible solutions at these problematic sites were pressurised distribution systems, i.e. low pressure pipe (LPP) or drip distribution (DD) systems (USEPA 1999; EPRI 2004), sealed basin evapotranspiration systems (Gregersen \& Brix 200I; Arias 20I2; Curneen \& Gill 20I4) as well as closed collection tanks (cesspools) with regular emptying (Norström et al. 2008) and disposal at centralised wastewater treatment plants. Where the impermeable soil layer is shallow enough, the discharge of treated effluent through an imported media filter into more permeable subsoil or bedrock was also considered. Furthermore, the possibility to connect houses to the nearest existing sewer network or the feasibility of clustering together several houses that could be served by a decentralised treatment plant with a consented discharge to a watercourse were assessed.

A modelling architecture (decision matrix) (Figure 1) was developed for the various scenarios, incorporating the use of geospatial datasets of human settlements, the physical environment comprising geology, land cover and hydrology, and infrastructure such as transportation and utility networks. It takes as its initial input the location of an existing house within an area of low permeability subsoils. The proposed six solutions and their suitability for the selected site are then evaluated in parallel. While the onsite solutions are always included as suggested options, the selection of other appropriate solutions depends principally on four major model parameters: distance from an existing sewerage network; existing OSWWTS density (for reasons of economies of scale); the distance to surface water; and the depth to bedrock. Through a series of interconnected GIS geoprocesses the model outputs appropriate solutions

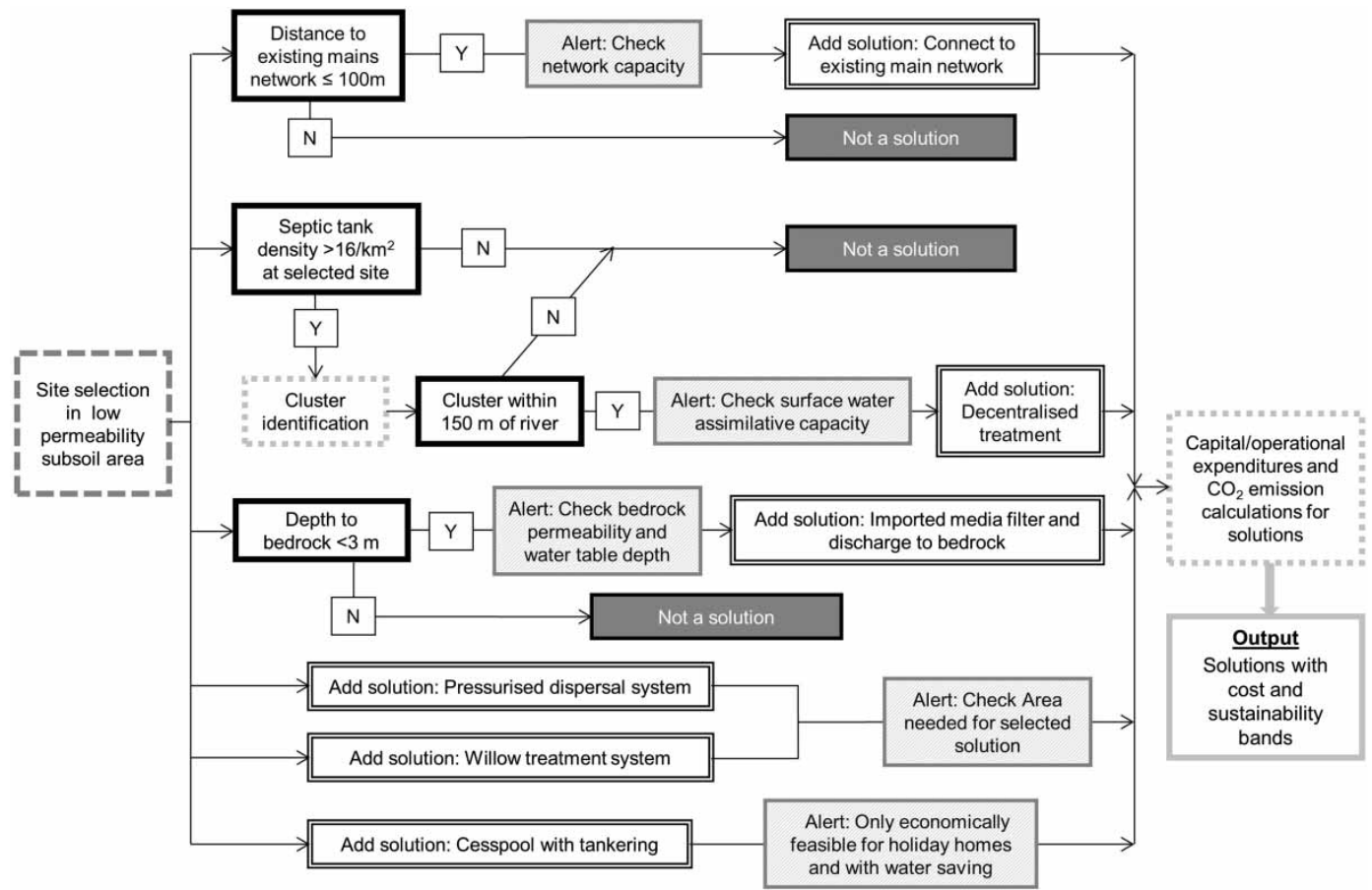

\begin{tabular}{|l|l|l|}
\hline Key: & User input \\
\hline
\end{tabular}

Figure 1 | Modelling architecture for the GIS-based decision support toolset. 
for a site. To assess the feasibility of each solution, capital and operational costs as well as operational sustainability calculations were established within the model. However, it should be noted that any final decisions are still dependent on on-site constraints. Therefore, each solution is accompanied by an alert message that provides additional information to refine the output list according to the available local site-specific information.

The subsequent coding has been carried out to initially test the programme on four counties (Wexford, Leitrim, Sligo and Limerick) within Ireland. The ArcGIS tools and functions that have been applied for each strategy evaluation will be explained in the results section. The model is set as a web service on the Amazon EC2 cloud as a simple, scalable and independent-rich internet application. It was developed using ESRI ArcGIS Server 10.1 and ArcMAP 10.1 and has been configured as a thin client/server application using Adobe Flash builder 4.6. The model will be placed as a web service on the ArcGIS server and exposed to the thin client through the representational state transfer protocol.

\section{RESULTS AND DISCUSSION}

Using the GIS maps and tools, existing OSWWTSs situated in areas of inadequate percolation were identified within the four test counties. The number of OSWWTSs installed in areas with a high (60-85\%) and very high (>85\%) likelihood of inadequate percolation vary from 8,500 (Sligo) to over 18,000 in County Wexford, which is largely dominated by clay soils. These potentially polluting sites represent $32 \%$ to $84 \%$ of all existing OSWWTSs in the different counties (Table 1), thus highlighting the need for such a decision support tool as part of an appropriate managing system.

Table 1 | Number of legacy septic tanks in areas of inadequate percolation within the four test counties

\begin{tabular}{|c|c|c|c|}
\hline County & $\begin{array}{l}\text { Total } \\
\text { number of } \\
\text { septic tanks }\end{array}$ & $\begin{array}{l}\text { Septic tanks in area } \\
\text { with high likelihood } \\
\text { of inadequate } \\
\text { percolation }\end{array}$ & $\begin{array}{l}\text { Proportion of septic } \\
\text { tanks in areas with } \\
\text { high likelihood of } \\
\text { inadequate } \\
\text { percolation, \% }\end{array}$ \\
\hline Leitrim & 11,064 & 9,348 & 84.5 \\
\hline Limerick & 31,346 & 10,227 & 32.6 \\
\hline Sligo & 17,428 & 8,534 & 49.0 \\
\hline Wexford & 37,133 & 17,874 & 48.1 \\
\hline
\end{tabular}

\section{Connection to existing sewer network}

For sites where a centralised wastewater treatment plant is close enough to treat and dispose wastewater, the feasibility of connecting to that network should be investigated. Hence, the ArcGIS Network Analyst was used to determine the road distance from a selected site to the edge of the closest sewered area. This tool was selected over a standard buffering or distance function in order to estimate the length of the required sewer connection along the road, with associated installation costs.

The maximum distance of $100 \mathrm{~m}$ (less than which the connection to an existing sewer network is considered a viable option) was chosen initially based on an existing bylaw in County Cavan that states that any dwelling within $100 \mathrm{~m}$ of mains sewerage must be connected. However, this distance can be changed according to the local authority's needs. Results from GIS analysis for the four test counties show that between 5 and 9\% of all potential legacy sites lie within a $100 \mathrm{~m}$ radius distance of an existing sewer network. These proportions increase accordingly when a larger radius distance around sewered areas is considered (Figure 2(a)), providing a potential solution to 3,400 (100 $\mathrm{m}$ radius) to 6,000 houses ( $250 \mathrm{~m}$ radius) within the four counties. However, the additional expenses for extending the sewerage network will need to be considered. It should also be noted that, while the programme might suggest the connection to an existing sewer network as a viable solution, the available treatment capacity for the specific treatment facility will still need to be checked, as indicated by an appropriate alert message.

\section{Clustering of houses with decentralised wastewater treatment and surface water discharge}

The density of OSWWTSs in areas of inadequate percolation is calculated in order to determine whether it would be feasible to connect several houses via a small bore sewer network that feeds a decentralised treatment plant with a licensed discharge to surface water. This solution would have the advantage of only requiring a single discharge consent which covers several houses. In this context the house density is mainly important for reasons of economically feasibility; however, OSWWTS density is also an important factor when assessing the risk of groundwater and/or surface water contamination. For example, the US EPA suggests that any density greater than 16 systems $/ \mathrm{km}^{2}$ constitutes a 'region of potential contamination' (Yates I985). 

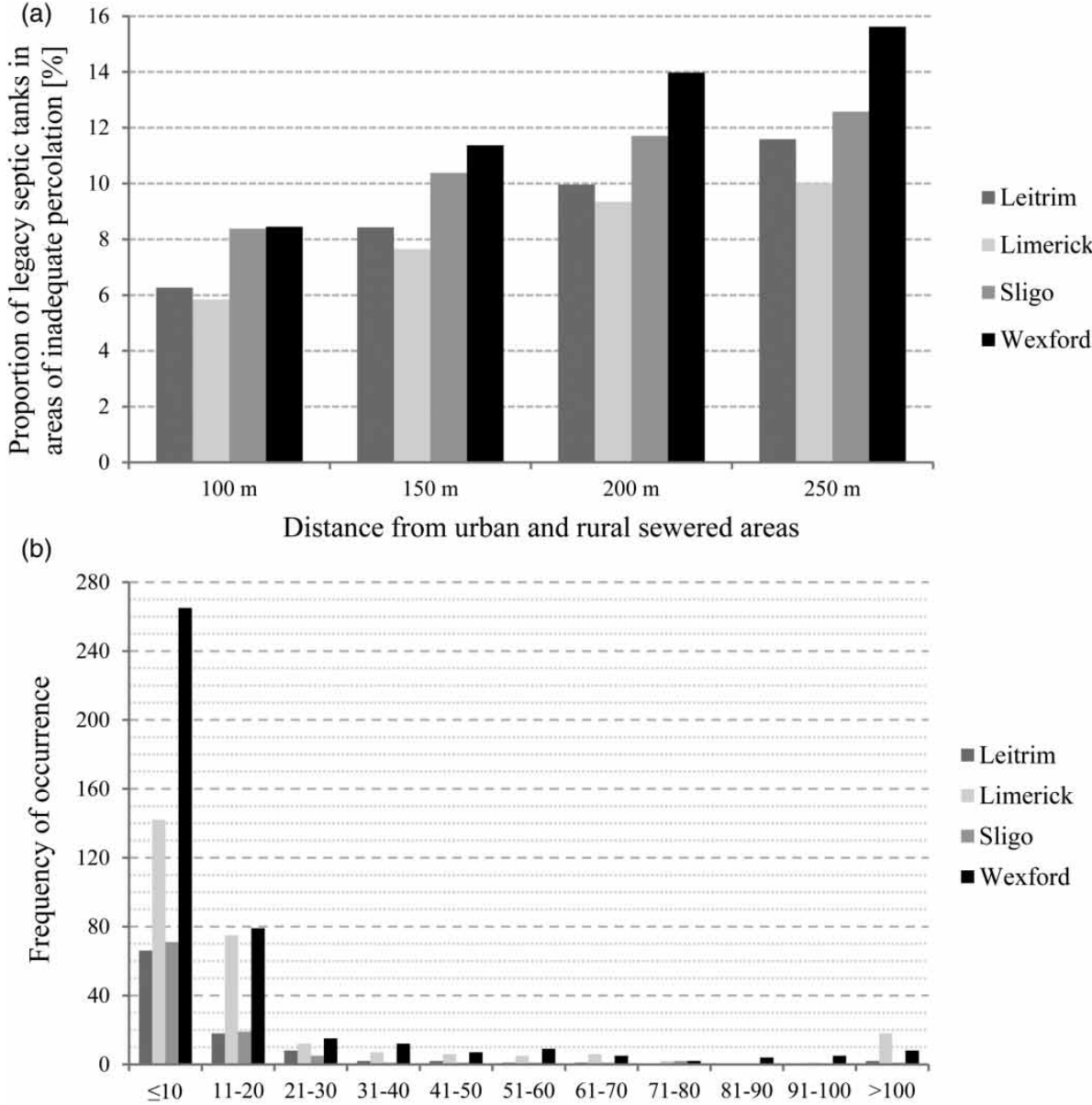

(c)

Cluster sizes

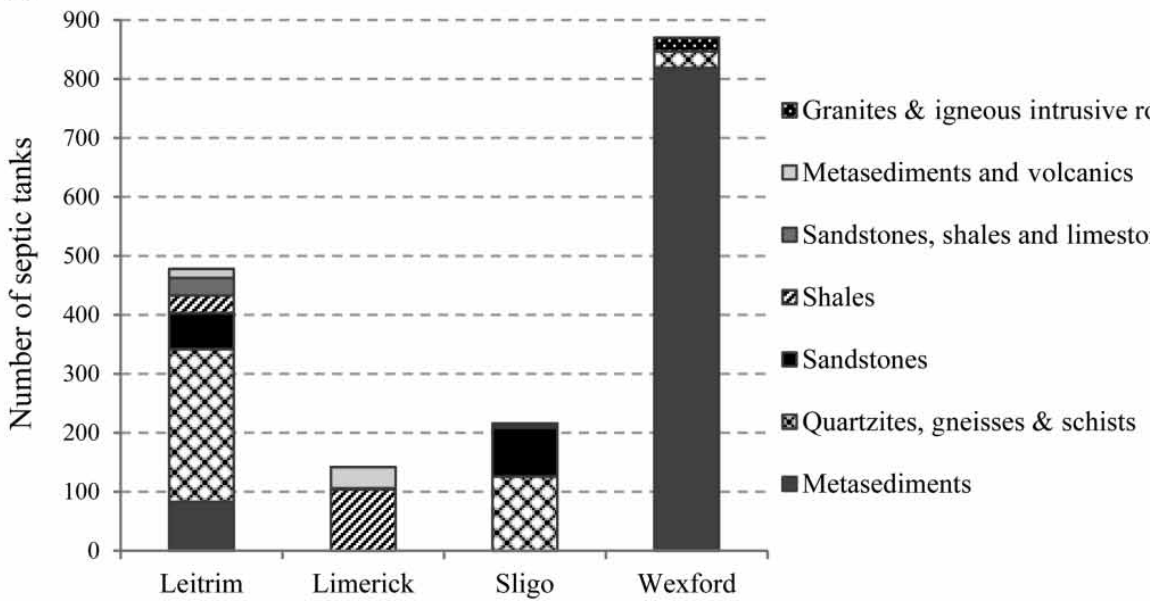

Figure 2 | Results from GIS analyses. (a) Proportion of legacy septic tanks in areas of inadequate percolation which are in close distances to urban and rural sewered areas in the four test counties. (b) Distribution of cluster sizes for possible decentralised treatment systems in the four test counties (minimum cluster size of four houses; 80 m as maximum distance between houses; $150 \mathrm{~m}$ as maximum distance to watercourse). (c) Number of septic tanks for which discharge to bedrock would be considered within the four test counties and the expected bedrock types at those sites.

The ArcGIS kernel density function was used to calculate house densities in rural areas. If the OSWWTS density in the area of a selected site is greater than 16 systems $/ \mathrm{km}^{2}$, an iterative buffering and clipping sequence (illustrated in Figure 3) is used to identify houses that are close enough to be connected to a small decentralised sewer system. In 


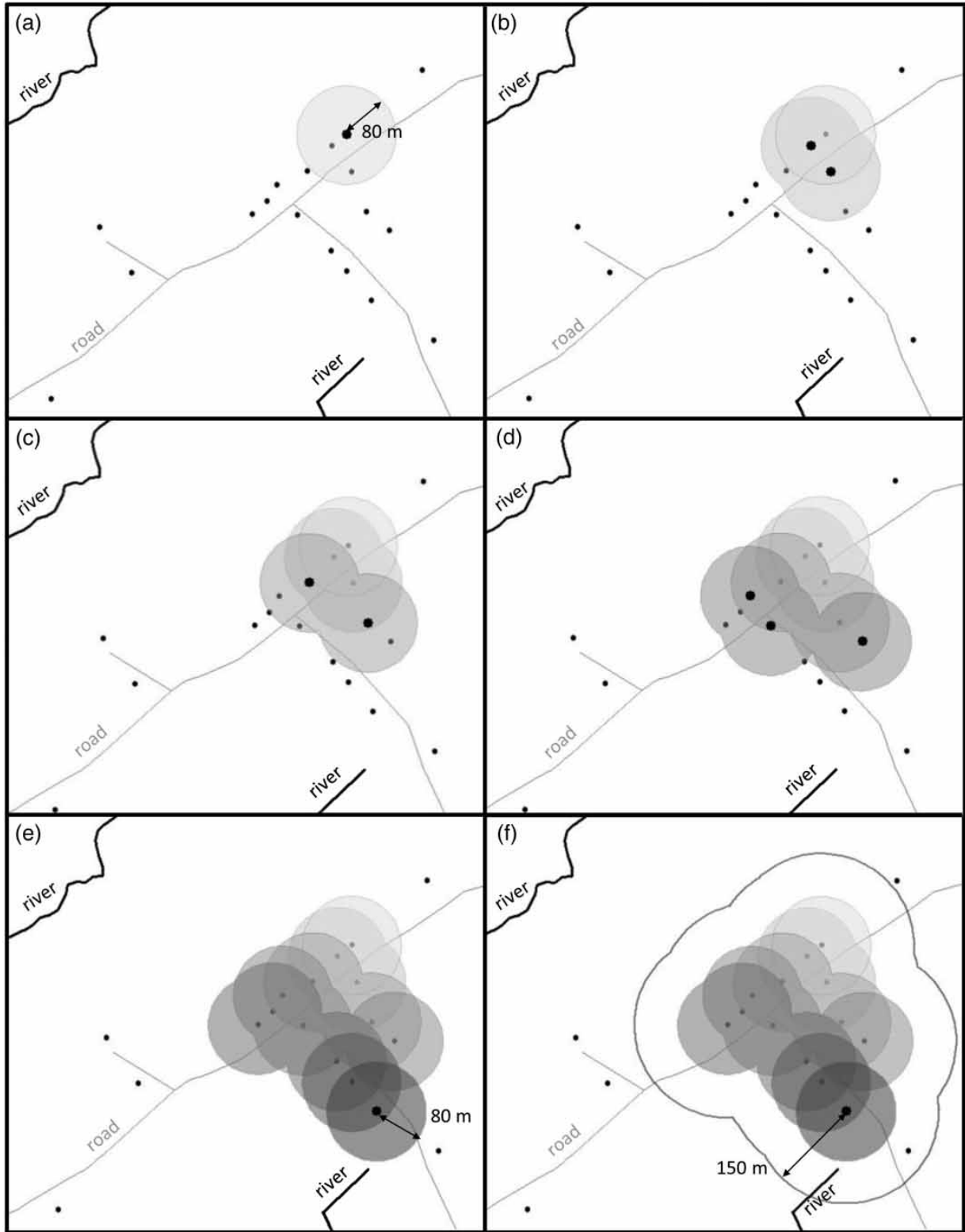

Figure 3 | Iterative buffer and clipping sequence to identify clusters of houses and watercourse for possible discharge: (a) selection of initial site and first buffer, (b) selection of houses within first buffer and second iteration, (c) third buffer iteration, (d) fourth buffer iteration, (e) final buffer without further houses, (f) buffer around cluster to intersect with river layer.

order to keep the bore sewer length (and therefore costs) to a minimum, only houses that are within $80 \mathrm{~m}$ distance of each other are included in the cluster. A buffer of $150 \mathrm{~m}$ around the final cluster is then intersected with the river polygon layer to find a potential surface water discharge point (Figure 3(f)). The houses included in the cluster as well as the river proposed for effluent discharge are graphically highlighted on the map displayed on the user interface. Where no river can be found at a reasonable distance to the cluster, the option of a decentralised wastewater treatment system is dismissed.

Based on this approach clusters comprising at least four houses were identified in areas of high likelihood of inadequate percolation within the four test counties (Table 2). Where clusters expand into areas with lower risks of percolation issues, those houses are included in the cluster as well. Around 200 clusters were identified in Leitrim and Sligo while 469 and 928 clusters were found 
Table 2 Clusters identified in the four test counties. The maximum distance between houses in the cluster is $80 \mathrm{~m}$ and only clusters containing a minimum of four houses are considered. Numbers in brackets represent clusters with a river within $150 \mathrm{~m}$ distance

\begin{tabular}{llll} 
& Leitrim & Limerick & Wexford \\
\hline Number of clusters & $197(100)$ & $469(274)$ & $230(102)$ \\
Max. cluster size & 196 & 592 & 164 \\
Average cluster size & $13(15)$ & $23(30)$ & $11(13)$ \\
Number of houses in all clusters & $2,469(1,474)$ & $10,580(8,251)$ & $2,517(1,298)$ \\
Number of legacy sites in clusters & $2,178(1,226)$ & $4,860(3,392)$ & $2,182(1,094)$ \\
\% of legacy sites within county & 13.1 & 33.2 & $12,860(7,229)$ \\
\hline
\end{tabular}

in the more densely populated counties of Limerick and Wexford, respectively (Table 2). Equally, the average cluster size varies from 11 in Sligo to 23 in Limerick where the largest clusters, comprising 500-600 houses, were found. Due to the larger clusters and the lower proportion of legacy sites in Limerick (Table 1), clusters more often expand into and include houses in areas of adequate subsoil permeability (Table 2). Where these represent the majority of houses within the cluster, the feasibility of a decentralised treatment solution and the installation of a large sewer network need to be revised.

When excluding those clusters that are further than $150 \mathrm{~m}$ away from a watercourse, about half of the identified clusters (44.3-58.4\%) could still be considered for a decentralised wastewater treatment solution. These clusters represent $12.8,13.1,33.2$ and $33.9 \%$ of all legacy sites in areas of low subsoil permeability in Sligo, Leitrim, Limerick and Wexford respectively. Figure 2(b) shows the distribution of cluster sizes for considered decentralised treatment solutions. Although the largest clusters have been found close to rivers, increasing the average cluster sizes slightly (Table 2) still results in over $80 \%$ of clusters comprise less than 21 houses. It has also been noticed that larger clusters are usually found close to sewered areas; for example in Counties Sligo and Wexford the average cluster sizes in these areas were 29 and 33, respectively, and hence significantly higher than for the overall counties. It could also be seen that 17 and 51 clusters of those not considered for decentralised treatment due to the absence of a suitable surface water discharge point were actually close to sewered areas, so that a decentralised sewer network could be considered that would be fed into the adjacent centralised sewer system. This would provide a solution to another $332(3.9 \%)$ and 1,315 (7.4\%) legacy sites in Sligo and Wexford, respectively.

Overall these results show that decentralised treatment could provide a solution particularly for more densely populated counties such as Limerick and Wexford and in areas close to urban centres and larger rural towns. However, it should be noted that cluster sizes within more rural areas will increase when a larger maximum distance between houses (e.g. 100 or $120 \mathrm{~m}$ ) is considered. The economical feasibility of increasing this parameter value within the programme still remains to be tested.

However, before the proposed discharge from such a decentralised wastewater treatment plant to surface water can be considered, the assimilative capacity of the proposed receiving river needs to be assessed (which the user is again notified by an on-site constraint alert).

\section{Discharge onto bedrock through imported media filter}

Another option is to evaluate whether the depth of low permeability subsoil is shallow enough to be replaced by a more suitable imported medium (soil or sand) through which treated effluent will percolate down into the bedrock. A maximum depth of $3 \mathrm{~m}$ was considered to be economically realistic for the excavation of the existing subsoil. Hence, the depth to bedrock for the selected site location was obtained from GIS maps to determine whether this would be a possible treatment and disposal option. However, additionally a minimum depth $(1 \mathrm{~m})$ of unsaturated zone is needed to ensure sufficient treatment within the soil/sand filter before the water table; so it is advised to carry out an on-site assessment to determine the water table depth. Furthermore an assessment of the bedrock permeability will be required to ensure that it will be able to take the hydraulic load. GIS layers mapping the bedrock types within Ireland give an indication of the expected hydraulic properties. Generally sedimentary rocks (e.g. limestone and sandstone) have higher hydraulic conductivities than igneous rocks such as granite; however, the actual permeability is largely affected by the depth and extent of fracturing and weathering. While unfractured intrusive igneous rocks can be nearly 
impermeable, weathered granite and fractured igneous rocks can have hydraulic conductivities of up to $5.2 \times 10^{-5}$ and $3 \times 10^{-4}$, respectively (Domenico \& Schwarz 1990). Hence, in certain areas an individual site assessment to determine whether the local bedrock has the required permeability might be inevitable.

Figure 2(c) shows how many houses located in areas with high likelihood of inadequate percolation would have a maximum subsoil depth of $3 \mathrm{~m}$. It also includes information on the type of bedrock that can be expected underneath the shallow subsoil at those sites. The results show that this solution would be potentially suitable for 478, 142, 216 and 870 houses in Leitrim, Limerick, Sligo and Wexford, respectively. This would represent 5.1 and 4.9\% of the legacy sites in Counties Leitrim and Wexford but only 2.5 and $1.4 \%$ in Sligo and Limerick, respectively. While most sites in Limerick are underlain with shales (73\%) the predominant bedrock for sites in Wexford (94\%) are formed of metasediments. About half of the sites in Leitrim and Sligo are underlain with potentially impermeable metamorphic rocks such as quartzites, gneisses and schist but both counties also have sites on permeable bedrock such as sandstone and limestones.

\section{On-site treatment systems}

The remaining on-site solutions that would be suitable at a single house scale are always considered by the programme, as the suitability of these systems is mainly dependent on site-specific constraints that are not available from GIS maps. Hence the user will be given additional information together with the suggested solution that enables the user to refine the output list according to local site-specific information.

The suitability of LPP and DD systems for example will depend primarily on the site-specific subsoil permeability. The permeability is tested as part of a compulsory site assessment in Ireland using a falling head percolation test (T-test) (Mulqueen \& Rodgers 20oI). The programme user will be supplied with the applicable maximum T-values for these systems, such that the solution can be included or excluded based on the available site information. Where the T-value is already known it can also be entered in a designated field at the user interface, allowing solutions to be automatically selected or rejected. Furthermore, as the required area for effluent dispersal increases with decreasing subsoil permeability, the size of the system might be prohibitive. Reducing the daily effluent load via the use of water saving devices can significantly reduce the required area for LPP and DD systems; so information about minimum required areas with and without water saving devices are displayed with the programme output.

Zero-discharge solutions, such as evapotranspiration systems (often known as willow systems) or a large sealed cesspool tank in which the effluent collects until it is periodically tankered away to a centralised treatment facility, could be applicable at any site, regardless of subsoil permeability. However, both solutions have their own on-site constraints. Willow systems typically require a large surface area (80 to $110 \mathrm{~m}^{2}$ per person) which might restrict their suitability for certain sites, and so an alert to check the on-site land area availability will be displayed (both with and without water saving assumed). For the cesspool a low wastewater production will be crucial to make this option economically feasible. Hence, this disposal option is only considered in connection with water saving devices and is only recommended for holiday homes.

\section{Cost and sustainability ranking}

To provide the opportunity to evaluate the alternative disposal options on the basis of both cost-benefit and environmental sustainability principles, calculations to estimate capital and operational costs as well as greenhouse gas (GHG) emissions associated with each solution have been established. Capital cost estimations comprise material and installation costs, including the labour required for the systems' installation. Operational costs include running costs (resulting mainly from the systems' electricity usage) as well as maintenance costs that arise for the householder for system services and desludging. Environmental sustainability is only estimated for the systems' operation and is primarily based on the $\mathrm{CO}_{2}$ emission related to the electricity usage and the diesel usage for desludging.

All costs are calculated with and without the use of water saving devices which have been shown to reduce significantly a household's wastewater production and hence both capital and operational costs of certain disposal systems (Dubber \& Gill 2013). Cost savings related to the water and energy savings achieved by water saving devices are charged against operational costs. A similar approach is used for the assessment of operational GHG emissions.

All cost and emission calculations integrate and use results from GIS-based computational tasks as input 
parameters for their estimations. Examples are the road distance of a house to the nearest sewer network, the size of suggested house cluster, and the distance from a house to the next wastewater treatment plant for sludge or wastewater disposal. Hence, the costs and environmental sustainability rankings for the different solutions are site specific. However, general trends show that evapotranspiration systems are one of the most expensive solutions in terms of capital costs, even with the use of water saving devices, but operational costs and GHG emissions are the lowest, especially when designed as a gravity flow system. In addition, the energy savings from water saving devices and associated lower water heating will reduce the household's $\mathrm{CO}_{2}$ footprint.

\section{CONCLUSIONS}

The developed decision support toolset can be used by environmental planners and managers to assess the feasibility of different sewage treatment and disposal systems for houses in rural areas with low permeability subsoils. It should be noted that the model is designed to be a decision support tool. Its precision is largely dependent on the accuracy of available geospatial data and final decisions would obviously still be dependent on on-site constraints and assessments to refine the output solutions. However, this will help to improve the management of on-site wastewater treatment and consequently help to protect ground and surface water from faecal pollution and eutrophication, protecting water resources and improving human health. The developed programme has now been handed over to the Irish Environmental Protection Agency and a case study is currently being carried out to demonstrate how the tool can be used in order to establish remediation strategies for OSWWTSs in catchments with low subsoil permeabilities where surface waters are at risk of failing the EU Water Framework Directive (CEC 200o) objectives.

\section{ACKNOWLEDGEMENT}

Acknowledgment is given to the Irish Environmental Protection Agency for funding this research.

\section{REFERENCES}

Arias, C. A. 2012 Current state of decentralized waste water treatment technology in Denmark. In: EPA International Symposium on Domestic Wastewater Treatment and Disposal Systems, Trinity College Dublin, Dublin, Ireland.

CEC (Council of the European Communities) 2000 Directive 2000/60/EC of the European Parliament and of the Council of 23 October 2000 establishing a framework for Community action in the field of water policy OJ L327, 22 December, $1-73$.

CSO 20 II Census 2011 - Principal Demographic Results. Central Statistics Office GoI, Stationery Office, Dublin.

Curneen, S. \& Gill, L. 20I4 A comparison of the suitability of different willow varieties to treat on-site wastewater effluent in an Irish climate. Journal of Environmental Management 133, 153-161.

Domenico, P. A. \& Schwarz, F. W. I99o Physical and Chemical Hydrogeology. Wiley, New York.

Dubber, D. \& Gill, L. 2013 Improving the feasibility of on-site wastewater treatment systems in areas of low permeability subsoils by means of water saving technologies. In: 11th IWA Conference on Small Water \& Wastewater Systems and Sludge Management, Harbin, China.

EPA 2009 Code of Practice: Wastewater Treatment and Disposal Systems Serving Single Houses. Environmental Protection Agency, Wexford, Ireland.

EPA 2013 A Risk-Based Methodology to Assist in the Regulation of Domestic Waste Water Treatment Systems, Environmental Protection Agency, Wexford, Ireland.

EPRI 2004 Wastewater Subsurface Drip Distribution: Peer Reviewed Guidelines for Design, Operation, and Maintenance, Electric Power Research Institute, Palo Alto, TN, USA.

Gill, L. W., O'Sulleabhain, C., Misstear, B. D. R. \& Johnston, P. J. 2007 The treatment performance of different subsoils in Ireland receiving on-site wastewater effluent. Journal of Environmental Quality 36 (6), 1843-1855.

Gregersen, P. \& Brix, H. 200I Zero-discharge of nutrients and water in a willow dominated constructed wetland. Water Science and Technology 44 (11-12), 407-412.

Mulqueen, J. \& Rodgers, M. 20or Percolation testing and hydraulic conductivity of soils for percolation areas. Water Research 35 (16), 3909-3915.

Norström, A., Erlandsson, Å. \& Kärmann, E. 2008 Environmental assessment and cost estimation of drinking water and wastewater systems for transition areas in Sweden. In: 8th Specialised IWA Conference on Small Water and Wastewater Systems, Coimbatore, India.

USEPA 1999 Decentralized Systems Technology Fact Sheet. Low Pressure Pipe Systems. United States Environmental Protection Agency, Office of Water, Washington, DC.

Yates, M. V. 1985 Septic tank density and ground-water contamination. Ground Water 23 (5), 586-591.

First received 8 January 2014; accepted in revised form 15 May 2014. Available online 27 May 2014 